\title{
Insect Rate-Temperature Relationships: Environmental Variation and the Metabolic Theory of Ecology
}

\author{
Ulrike M. Irlich, ${ }^{1}$ John S. Terblanche, ${ }^{2}$ Tim M. Blackburn, ${ }^{3}$ and Steven L. Chown ${ }^{1, *}$ \\ 1. Centre for Invasion Biology, Department of Botany and Zoology, Stellenbosch University, Private Bag X1, Matieland 7602, South \\ Africa; 2. Department of Conservation Ecology and Entomology, Stellenbosch University, Private Bag X1, Matieland 7602, South Africa; \\ 3. Institute of Zoology, Zoological Society of London, Regents Park, London NW1 4RY, United Kingdom
}

Submitted March 10, 2009; Accepted August 5, 2009; Electronically published October 27, 2009

Online enhancement: zip file. Dryad data: http://hdl.handle.net/10255/dryad.865.

ABSTRACT: Much of the recent discussion concerning the form and underlying mechanistic basis of metabolic rate-temperature and development rate-temperature relationships has been precipitated by the development of the metabolic theory of ecology (MTE). Empirical tests of the theory's fundamental equation are an essential component of establishing its validity. Here, we test the temperature component of the fundamental equation of the MTE as it applies to metabolic rate and development rate, using insects as model organisms. Specifically, we test (i) whether mean activation energies, $E$, approximate the $0.65 \mathrm{eV}$ value proposed by the proponents of the MTE and whether the range of values is tightly constrained between 0.6 and $0.7 \mathrm{eV}$, as they have argued; (ii) whether phylogenetic signal is apparent in the rate-temperature relationships; (iii) whether the slopes of the rate-temperature relationships show consistent, directional variation associated with environmental variables; and (iv) whether intra- and interspecific rate-temperature relationships differ significantly. Because the majority of activation energy values fell outside the predicted range and rate-temperature relationships showed consistent directional variation correlated with large-scale climatic variation, we conclude that data from insects provide only limited support for the MTE. In consequence, we consider alternative explanations for variation in rate-temperature relationships.

Keywords: growth rate, interspecific relationships, intraspecific relationships, metabolic rate, temperature dependence.

\section{Introduction}

The thermal sensitivity of physiological rates is one of the most significant characteristics of all organisms. It is especially important in ectotherms, which frequently have a more limited scope for thermoregulation than do endotherms and so are more susceptible to changing environmental temperatures (Cossins and Bowler 1987; Deutsch et al. 2008; Angilletta 2009; Huey et al. 2009). In

* Corresponding author; e-mail: slchown@sun.ac.za.

Am. Nat. 2009. Vol. 174, pp. 819-835. (c) 2009 by The University of Chicago. 0003-0147/2009/17406-51135\$15.00. All rights reserved.

DOI: $10.1086 / 647904$ consequence, ectotherms are characterized by a wide range of physiological responses that alter the extent and form of the rate-temperature response. For example, terrestrial ectotherms from temperate environments often show elevated metabolic rates or changes in the slope of the ratetemperature relationship when compared with their more tropical counterparts (Sømme and Block 1991; Chown and Gaston 1999; Yamahira et al. 2007). Similarly, lower developmental threshold and the sum of effective temperatures vary with latitude in both plants and arthropod ectotherms, such that a negative relationship exists between these two characteristic parameters of the development rate-temperature relationship (Honěk 1996a, 1996b; Ikemoto 2005; Trudgill et al. 2005). Such responses are unsurprising, given that variations in metabolic rate and development rate have direct impacts on fitness (Birkemoe and Leinaas 2000; Kozłowski et al. 2004; de Jong and van der Have 2008) and also have considerable significance in both theoretical and applied biology (e.g., Brown et al. 2004; Trudgill et al. 2005). Nonetheless, the form and significance of these responses are not without controversy.

In the case of metabolic rate, it has been argued that elevation in absolute rate with environmental temperature, or some proxy thereof, such as latitude (also known as metabolic cold adaptation), either has no sound theoretical basis or accounts for so little variation in rate that it is insignificant (see discussion in Clarke 1993, 2003, 2004; Chown and Gaston 1999; Gillooly et al. 2006). Likewise, while early studies suggested that polar terrestrial ectotherms should have lower slopes of the rate-temperature relationship than their more temperate or tropical counterparts, later work suggested that the opposite might be the case (see Sømme and Block 1991; Chown 1997). For development rate-temperature relationships, the most biologically appropriate equation describing the form of the relationship, the constancy of thermal windows, and the extent of development rate isomorphy have all been the 
subjects of significant interest (e.g., Sharpe and DeMichele 1977; Schoolfield et al. 1981; Gillooly et al. 2002; Jarošík et al. 2002; Charnov and Gillooly 2003; Kontodimas et al. 2004; de Jong and van der Have 2008; Dixon et al. 2009). At the heart of much of the recent discussion lies the fundamental equation of the metabolic theory of ecology (MTE), a theory that suggests that variation in metabolic rate can account for much of the variation in population parameters, generation times, and mutation rates of organisms (Gillooly et al. 2002, 2005; Ernest et al. 2003; Savage et al. 2004a; Frazier et al. 2006), ultimately explaining variation in speciation rates across the planet and large-scale patterns in biodiversity (Allen et al. 2002, 2006; Allen and Gillooly 2006; but see also Thomas et al. 2006; Algar et al. 2007; Hawkins et al. 2007).

The fundamental equation of the MTE posits that basal (or standard) metabolic rate varies principally as a consequence of organismal body mass and environmental temperature in the following manner (Gillooly et al. 2001; Brown et al. 2004):

$$
Y=b_{0} M^{b} e^{-E / K T}
$$

where $Y$ is metabolic rate, $M$ is body mass, $b$ is a universal scaling exponent (assumed to be $3 / 4$ ), $b_{0}$ is a taxon-specific constant, $E$ is the mean activation energy of the respiratory complex, $k$ is Boltzmann's constant $\left(8.617 \times 10^{-5} \mathrm{eV} / \mathrm{K}\right)$, and $T$ is the absolute environmental temperature $(\mathrm{K})$.

Both the mass and the temperature components of this fundamental equation of the MTE have been the subject of contention, although most of the attention has been focused on the former (see Kozłowski and Konarzewski 2004; Savage et al. 2004b; Glazier 2005; for a recent exchange, see Allen and Gillooly 2007; O'Connor et al. 2007). By contrast, discussion of the way in which temperature affects metabolic rate has been less extensive (Terblanche et al. 2007).

Gillooly et al. (2001) proposed that the many different reactions that comprise metabolic rate each depend on the concentration of reactants, their fluxes, and the kinetic energy of the system. The first two terms are accounted for by mass dependence, while the third term incorporates the major influence of temperature, which is in turn governed by simple Boltzmann kinetics (West et al. 1997; Brown et al. 2004; West and Brown 2005). This temperature dependence term of the fundamental equation of the MTE has been called the universal temperature dependence (UTD; Gillooly et al. 2001) because the activation energy, $E$, is apparently relatively invariant among organisms. This claim has been made in a variety of ways. Citing Raven and Geider (1988) and Vetter (1995), Gillooly et al. (2001, p. 2249) argued that $E$ should "vary between 0.2 and $1.2 \mathrm{eV}$ with an average of $0.6 \mathrm{eV}$." They provided metabolic rate-temperature plots for seven groups of organisms and argued that "the average activation energies extracted from the slopes give $E_{i}=0.41-0.74 \mathrm{eV}$ with a mean for all groups of $0.62 \mathrm{eV}$," thus supporting their prediction (although from the plots in their fig. 1, the values range between 0.43 and 0.79 , with a mean of 0.67 $\mathrm{eV}$ ). Gillooly et al. (2002) argued again for "an average activation energy for metabolic reactions of $0.6 \mathrm{eV}$ (range between approximately 0.2 and $1.2 \mathrm{eV}$ )" and used another seven relationships to provide support for it (the values from these plots range from 0.64 to $0.9 \mathrm{eV}$, with a mean of $0.77 \mathrm{eV}$ ). Gillooly et al. (2005) suggested that $E \approx$ 0.65, and West and Brown (2005, p. 1583) did likewise. Later, Gillooly et al. (2006) argued that the MTE "predicts that $E$ takes on a limited range of values, $0.6-0.7 \mathrm{eV}$ with an average of $0.65 \mathrm{eV}$," while Allen and Gillooly (2007, p. 1075) made clear that "the average activation energy of respiration is predicted to fall between 0.6 and $0.7 \mathrm{eV}$ (and not $0.2-1.2 \mathrm{eV}$, as sometimes suggested)." The original works by Raven and Geider (1988), Vetter (1995), and McLeese and Eales (1996) provide a range of values from 0 to $1.45 \mathrm{eV}$. In consequence, the expected mean value for $E$ of $0.65 \mathrm{eV}$ (with variation between 0.6 and $0.7 \mathrm{eV}$ ), or UTD, should perhaps be seen more as an empirical approximation suggested by the MTE than as a theoretical prediction. However, it is important to bear in mind that both Gillooly et al. (2006) and Allen and Gillooly (2007) have explicitly stated that the $0.6-0.7 \mathrm{eV}$ value for $E$ is a prediction of the MTE. We therefore treat the current assessment thereof as such.

The validity of the UTD has subsequently been questioned on several grounds. For example, Clarke (2004) argued that the UTD as described by Gillooly et al. (2001; termed the hard UTD hypothesis) predicts a similar among- and within-species rate-temperature relationship, whereas the alternative, the evolutionary trade-off (ETO) hypothesis, he proposed, predicts a steeper intraspecific relationship (see also Clarke 2003). Gillooly et al. (2006) have responded to these criticisms (see also Allen and Gillooly 2007), arguing that the UTD continues to explain a very large proportion of variation in mass-corrected metabolic rates and that evolutionary adaptation, acclimatization, and acclimation are reflected predominantly in changes to $b_{0}$ of the fundamental equation. They also noted that some variation about the rate-temperature relationships is to be expected and therefore that the hard UTD hypothesis does not necessarily predict identical withinand among-species relationships. Clarke (2006) has responded to several of these arguments, and more recently, Brown and Sibly (2006, p. 17595) have again stated that the fundamental equation of the MTE "holds both within and between species."

From the above discussion, it should also be clear that 
proponents of the MTE are of the view that other biological rates, such as heart rate, growth rate, and development rate, vary with mass and temperature in a fashion similar to that described for metabolic rate (Gillooly et al. 2001, 2002; West et al. 2001; Charnov and Gillooly 2003; Brown et al. 2004). For example, embryonic development rate is considered a function both of mass and of temperature, with the relationship being described, at its simplest, as

$$
\frac{d m}{d t}=a m^{3 / 4},
$$

where $d m / d t$ is growth rate, $m$ is embryonic mass, and $a$ is a function of $b_{0}$ (the normalization factor for metabolic rate; see Gillooly et al. 2001) and the mass of a cell and the energy required to grow it (Gillooly et al. 2002). As might be expected, given that $a \propto b_{0}$, the temperature dependence of $a$ is given by

$$
a(T) \propto \exp ^{(-E / k T)},
$$

where $E, k$, and $T$ are as described for equation (1). Like other aspects of the MTE, these ontogenetic growth models have also been vigorously criticized on several grounds (e.g., Ricklefs 2003; Makarieva et al. 2004), and the proponents have replied (West et al. 2004). The MTE proponents have also indicated that postembryonic growth is likely to show similar dependencies on mass and temperature (Gillooly et al. 2002; Brown et al. 2004). Nonetheless, as is the case with the UTD of metabolic rate, investigations of the temperature dependence of development rate have been much less extensive than studies of the way in which development rate scales with size. Nonetheless, a few investigations exist that directly examine the temperature dependence of development rate in the context of the MTE (Makarieva et al. 2004), consider the appropriateness of the temperature component of the fundamental equation in this context (de Jong and van der Have 2008), or test the ancillary predictions of the UTD, such as constancy of thermal windows (Dixon et al. 2009).

A critical point emerging from these discussions is that significant empirical tests of the fundamental equation of the MTE depend not so much on whether there is variation about the scaling and temperature terms but on what form that variation takes and whether it is in a consistent direction (Clarke 2004; Chown et al. 2007). Thus, the proponents of the MTE expect that once the effects of temperature and mass on rates have been taken into account, most of the remaining variation should be found in the normalization constant (Brown et al. 2004; Gillooly et al. 2006), with little directional variation about the slope of the rate-temperature and mass-scaling relationships (but see also discussion in Enquist et al. 2007a, 2007b). By contrast, alternative explanations, such as the ETO hypothesis proposed by Clarke (2004), the optimization hypothesis proposed by Kozłowski et al. $(2003 a, 2003 b)$, and the Sharpe-Schoolfield approach (see de Jong and van der Have 2008), predict that variation should be found in the slopes of the relationships and that directional variation in these slopes should be common, especially among different organisms and levels in the genealogical hierarchy. To date, only a single controversial data set on fish has been used to test these ideas in the context of the ratetemperature term of the fundamental equation of the MTE (Clarke 2004; Gillooly et al. 2006), although a limited assessment, based on data for Drosophila, is provided by de Jong and van der Have (2008).

Therefore, in this study, the temperature component of the MTE, as it applies to metabolic rate and development rate, and the form and directionality of variation about it are investigated, using insects as model organisms. Given that insects are such a diverse and abundant group of animals, comprising approximately $70 \%$ of extant animal species (Hawksworth and Kalin-Arroyo 1995), any universal model should apply to this group. Specifically, for both metabolic rate and development rate, the following claims of the MTE are examined: (i) $E$ should assume a mean value of $0.65 \mathrm{eV}$, with the majority of its values lying between 0.6 and $0.7 \mathrm{eV}$ (how many values exactly begs the question of what a rule or law is in biology [see, e.g., Mayr 1956; Lawton 1999; Gaston et al. 2008], but we arbitrarily select $>50 \%$ of values as a simple majority); (ii) little phylogenetic signal should be apparent in the slopes of the rate-temperature relationships; (iii) slopes of the rate-temperature relationships should show no directional environmental variation; (iv) intra- and interspecific ratetemperature relationships should not differ. The outcomes of these tests are then discussed in the context of ancillary predictions of the MTE (such as the constancy of thermal windows) and alternative explanations for the form and variation of rate-temperature relationships.

\section{Methods \\ Data Collection}

Temperature effects on metabolic rate and development rate have been extensively studied in insects (AddoBediako et al. 2002; Chown and Nicolson 2004; Trudgill et al. 2005; de Jong and van der Have 2008). To conduct a global investigation on the relationship between temperature and these two variables, the published Anglophone literature dating back as far as 1900 , with a major emphasis on the past 50 years (ending in 2006), was examined. Only studies that measured metabolic or devel- 
opment rate at three or more constant temperatures were considered.

From studies on adult insect metabolic rate-temperature relationships, the metabolic rate at each trial temperature, trial temperature, and body mass were extracted. For some species, the authors published only the regression equation of the metabolic rate-temperature relationships (five of 91 studies), which was then used to calculate the specific metabolic rates for each experimental temperature they had used. In studies that reported sex-related variation in metabolic rate-temperature relationships, the sex with the lower metabolic rate, together with its corresponding body mass, was used. The experimental method used to measure metabolic rate was scored as closed or flow-through respirometry because the former often results in higher estimates of metabolic rate (Lighton and Fielden 1995; Addo-Bediako et al. 2002). Furthermore, wing status (flying or nonflying) was noted for each species (determined mostly secondarily from taxonomic literature) because it is known that the ability to fly is generally accompanied by elevated standard metabolic rates (Reinhold 1999; Addo-Bediako et al. 2002).

A study was excluded if data for any of the above variables were not given. Laboratory colonies were excluded to eliminate the possible effects of laboratory adaptation and acclimation (see Chown and Terblanche 2007), and studies that tested the effect of gas concentrations, diet, or any other variables were not considered. Furthermore, when any doubt existed regarding the methods used, the quality of the data, or the activity state of the animals, the data were excluded. If multiple data for the same species were obtained from the literature, the species from the locality most unrepresented was chosen. This approach was necessarily iterative. In addition, where authors reported mortality or stress in individuals at a given temperature, data from this temperature were excluded, as were data from temperatures that resulted in better curvilinear than linear fits to the data (for discussion of linearity in the metabolic rate-temperature relationship, see Cossins and Bowler 1987). Metabolic rates were converted to microwatts ( $\mu \mathrm{W}$; Lighton 1991; Chown et al. 2007) as a standard unit, assuming a respiratory quotient of 0.84 , unless otherwise stated in the particular study. Furthermore, volumetric units were converted on the assumption of standard temperature and pressure.

From studies of development rate-temperature relationships, development time (days) at each trial temperature, trial temperature, and life stage were extracted. If development times were given for several life stages, they were summed to obtain times as close as possible to total development times (egg to adult development). In three cases, rate-temperature relationships of the various developmental stages of the same species were published separately. They were combined here to obtain developmental times of total egg-adult development because the methods and collection sites were identical. Where given, the adult body mass was also extracted from the study. However, because few developmental studies record body masses of the adults (Chown et al. 2002), these were secondarily determined from the primary literature where possible. For studies that investigated the effect of diet in conjunction with temperature, the developmental times were pooled, and the geometric mean of all diets, excluding artificial diets, was used to calculate development ratetemperature relationships. If the effect of humidity on development was tested, the humidity most beneficial for the species' development was chosen according to the authors' findings. If studies reported development rate for males and females separately, the geometric mean of the ratetemperature relationship of the two sexes was used. For each study it was noted whether the animals were field collected or reared for several generations in a laboratory.

A study was excluded if data for any of the above variables were not given. Studies that tested the effect of cold exposure before the development studies, unusual photoperiods, fluctuating temperatures, or the effects of crowding were not considered. Furthermore, when any doubt existed regarding the methods used or the quality of the data, the study was excluded. If multiple data for the same species were obtained from the literature, fieldcollected animals were chosen first and then the locality least represented in the database. This procedure was necessarily iterative as the database developed. In some cases, authors noted mortality at a particular temperature or a few temperatures. These data were excluded. Likewise, if rates at lower or upper temperatures meant a better fit of a curvilinear model to the data, these points were also excluded because the linear part of the relationship is usually investigated (e.g., Honěk 1996a, 1996b; Ikemoto 2005; Trudgill et al. 2005).

For each species only the biologically relevant temperature range required for normal development was selected, and temperatures detrimental to development were excluded. In some cases, these selections were at variance with what the authors of the original study may have suggested but in keeping with our consideration of the data. Although it is widely acknowledged that development rate and temperature show a nonlinear relationship and that this relationship is unimodal (e.g., Honěk and Kocourek 1990; Birkemoe and Leinaas 2000; Angilletta and Dunham 2003), as are so many performance curves (Huey and Stevenson 1979; Angilletta 2006), the aim here was to investigate the relationship over its linear range, as has been done previously (Campbell et al. 1974; Lamb 1992; Honěk 1996a, 1996b; Jarošík et al. 2002; Trudgill et al. 2005; de Jong and van der Have 2008) and as is implied by the 
MTE (i.e., ln rate vs. 1/temperature). All developmental times $(D)$ were converted to developmental rates $(1 / D)$.

\section{Climate Variables}

For each study on metabolic or development rate, the collection site was noted and its latitudinal and longitudinal positions recorded. If the latter were not presented in the original study, the information was obtained from an appropriate gazetteer. For studies that did not specifically state the geographic locality and where the species range, as could be ascertained from the literature, was not at odds with the assumption, the author's address was used as the locality. A suite of environmental variables was obtained from a high-resolution, interpolated climate database (http://www.diva-gis.org) with a $1-\mathrm{km}^{2}$ resolution and typically a time series of 50 years (Hijmans et al. 2005). Mean annual temperature (MAT), mean annual precipitation (MAP), temperature of the warmest quarter (TWQ), and precipitation of the warmest quarter (PWQ) were extracted for this study for the particular grid within which each species' locality fell. Temperature and precipitation seasonality, calculated from the mean monthly data, were also obtained from the climate database.

\section{Analyses}

Intraspecific Rate-Temperature Relationships. The slopes of the intraspecific relationships between temperature and natural logarithmic values of the metabolic and development rate were obtained by ordinary least squares regression of each species separately. Although other approaches could have been used, we assumed here that temperature control and measurement in the experiment were accurate, and so we retained the model I regression approach (see McArdle 1988). Because metabolic rate is strongly dependent on both temperature and body mass, it is often considered necessary to remove the effect of mass to determine the relationship between metabolic rate and temperature (Clarke and Johnston 1999). The interspecific scaling exponent for insects, when corrected for phylogenetic nonindependence, is $3 / 4$ (Chown et al. 2007). Thus, the metabolic rate of each species was divided by mass ${ }^{3 / 4}$, resulting in mass-corrected metabolic rate $\left(\mu \mathrm{W} / \mathrm{g}^{3 / 4}\right)$. Intraspecific development rates for total egg-adult development were not mass corrected because most authors do not report masses of the species they investigated (for the 506 species finally used here, masses for 119 species were found). In all cases, to obtain intraspecific activation energy $(E)$, a least squares linear regression of $\ln$ rate against inverse absolute temperature $(1 / k T)$ was used (see Cossins and Bowler 1987). The slope is then $-E$, which is reported in Dryad (http://hdl.handle.net/10255/dryad.865; also avail- able as a zip file). Throughout the text this value is positivized (see Cossins and Bowler 1987). Where slope data are used in raw form, these are the slopes of the ln ratetemperature relationships, which can be converted readily to $E$.

Before proceeding with the investigations of variation in slopes (or activation energies) at this level, it was necessary to determine whether the slopes of the metabolic rate-temperature relationships are likely to be influenced by artifacts associated with the method of data collection and by wing status. This was done using generalized linear models (see app. A).

To determine whether the intraspecific activation energies had a mean of $0.65 \mathrm{eV}$ and lay mostly between 0.6 and $0.7 \mathrm{eV}$, a single-sample $t$-test was applied, and the proportion of the empirical estimates lying between the values was determined, respectively. This was done separately for metabolic rate and development rate. The extent of environmental variation in the data was examined using generalized linear models (GLZs), assuming a normal distribution with a log-link function (McCullagh and Nelder 1989). First, following Addo-Bediako et al. (2002), it was determined whether variation in the slopes of the ratetemperature relationships could be explained by latitude and hemisphere. However, latitude is little more than a composite measure of environmental variation. Therefore, MAT and MAP, together with the seasonality of these two variables, were included with hemisphere in a second set of models. It has been argued that mean annual environmental data are not appropriate for use in macroecological studies, because most insects are typically inactive during the winter, and that data from the activity season of the species should be used (see Addo-Bediako et al. 2002; Chown et al. 2003; Hodkinson 2003). Therefore, the effects of TWQ and PWQ were also analyzed in a third set of models. In all cases, if confounding or biologically important variables such as respirometry method or wing status were significant in the previous assessments, they were included in the models (see app. A). In analyses incorporating environmental variables, only development rate-temperature relationships of field-collected animals were included because the latitudinal position for laboratory colonies does not necessarily indicate the true origin of the species and because environmental temperature for the locality is not a representative of the temperatures experienced by the animals.

The analyses described above were repeated to account for phylogenetic nonindependence, using the method of phylogenetic generalized least squares (PGLS; Grafen 1989; Martins and Hansen 1997). We compiled a supertree for this analysis, using data from the Tree of Life (http:// tolweb.org/tree/phylogeny.html) and from a wide variety of published phylogenies, modified from the one originally 
compiled by Chown et al. (2007). It is available on request. We assumed that all branches in this phylogeny were of equal length, although our conclusions are the same if the tree is assumed to be ultrametric, with branch lengths scaled by taxon richness. PGLS explicitly incorporates the expected covariance among species into a statistical model fit by generalized least squares. The correlation between error terms, which is assumed to be 0 in ordinary least squares, is thus altered in PGLS to reflect the degree of phylogenetic relatedness among the species. PGLS can be shown to be exactly equivalent to the widely used method of independent contrasts for a completely resolved phylogeny and the assumption that traits evolve by a Brownian motion model of evolution (Rohlf 2001). However, the covariance matrix can be modified in PGLS to accommodate the degree to which trait evolution deviates from Brownian motion, using a measure of phylogenetic correlation, $\lambda$ (Pagel 1999); $\lambda$ normally varies between 0 (no phylogenetic correlation) and 1 , with the value of $\lambda$ thus specifying the extent to which trait evolution is phylogenetically correlated. We used a maximum likelihood approach to estimate optimal $\lambda$ for each analysis (see also Halsey et al. 2006). In all cases, the models that best explained the variation in the rate-temperature relationships were selected using the Akaike Information Criterion (Burnham and Anderson 2002; Johnson and Omland 2004).

Interspecific Rate-Temperature Relationships. For both metabolic rate and development rate, interspecific ratetemperature relationships were also calculated. Previous assessments (e.g., Gillooly et al. 2001, 2002) have simply taken a single metabolic or development rate value (or set of values) at a specific experimental temperature (or a few temperatures) for a variety of species and then calculated the interspecific rate-temperature relationship for these species. This presumes that the experimental temperature used was representative of the thermal environments commonly encountered by the species concerned. Although this seems a reasonable assumption, it was reasoned that the form of the interspecific relationship might be substantially affected, especially if the experimental temperatures departed to any great extent or in any systematic fashion from environmental temperatures (see also AddoBediako et al. 2002; Chown et al. 2003; Hodkinson 2003). In particular, it is not uncommon for studies from cool environments to use temperatures slightly warmer than the MAT and those from warm environments to do the converse. Moreover, when dealing with studies for which a range of temperature data is available, it is not always clear which temperature should be selected as representative for the metabolic or development rate of that species, especially if authors do not report microclimate data, which is typically the case. Therefore, a range of approaches for determining the interspecific activation energy or slope of the rate-temperature relationship was adopted: namely, randomization, slopes using the rates closest to MAT or TWQ, slopes using rates at the MAT or TWQ calculated using interpolation, and slopes calculated using the median experimental temperature (for full descriptions see app. B).

In each case, activation energy was calculated from a least squares linear regression of $\ln$ rate against inverse absolute temperature $(1 / k T)$. The slope is then $-E$, which is reported in Dryad (also available as a zip file). Throughout the text this value is positivized (see Cossins and Bowler 1987). Where slope data are used in raw form, these are the slopes of the $\ln$ rate-temperature relationships, which can be converted readily to $E$.

Mass-corrected data were used throughout, which necessarily meant a substantial reduction in the development rate database: of the original 377 field-collected species, 85 were used here. The extent to which the six interspecific activation energy values included $0.65 \mathrm{eV}$ was examined by determining whether this value lay within the $95 \%$ confidence intervals (CIs). Thereafter, an assessment of the differences between the intraspecific and the interspecific relationships was made by determining whether the $95 \%$ CIs of the data for each of the levels overlapped for each of the six interspecific relationships, for metabolic rate, and for development rate.

\section{Results \\ Intraspecific Rate-Temperature Relationships}

The initial data set on adult insect metabolic rate-temperature relationships contained 129 species from nine orders and 37 families, but after excluding studies that examined groups of individuals, given the significant effects of grouping on metabolic rate (see app. A), the database contained 91 species in eight orders and 22 families ("Species Used for the Intraspecific Metabolic Rate-Temperature Analyses," available in Dryad or as a zip file). Total development time from egg to adult was obtained for a total of 506 species in 101 families and 12 orders ("Species Used for the Intraspecific Development RateTemperature Analyses," available in Dryad or as a zip file). No difference in rate-temperature relationships was found for laboratory and field-collected animals (app. A).

The mean intraspecific activation energy of $0.62 \mathrm{eV}$ for the metabolic rate-temperature relationship was not significantly different from the value of $0.65 \mathrm{eV}(95 \%$ $\mathrm{CI}=0.590-0.654, t=1.76, \mathrm{df}=90, P>.05)$ proposed by the MTE, although only $31 \%$ of the values lay between 0.6 and $0.7 \mathrm{eV}$ (fig. 1A). In the case of the development 

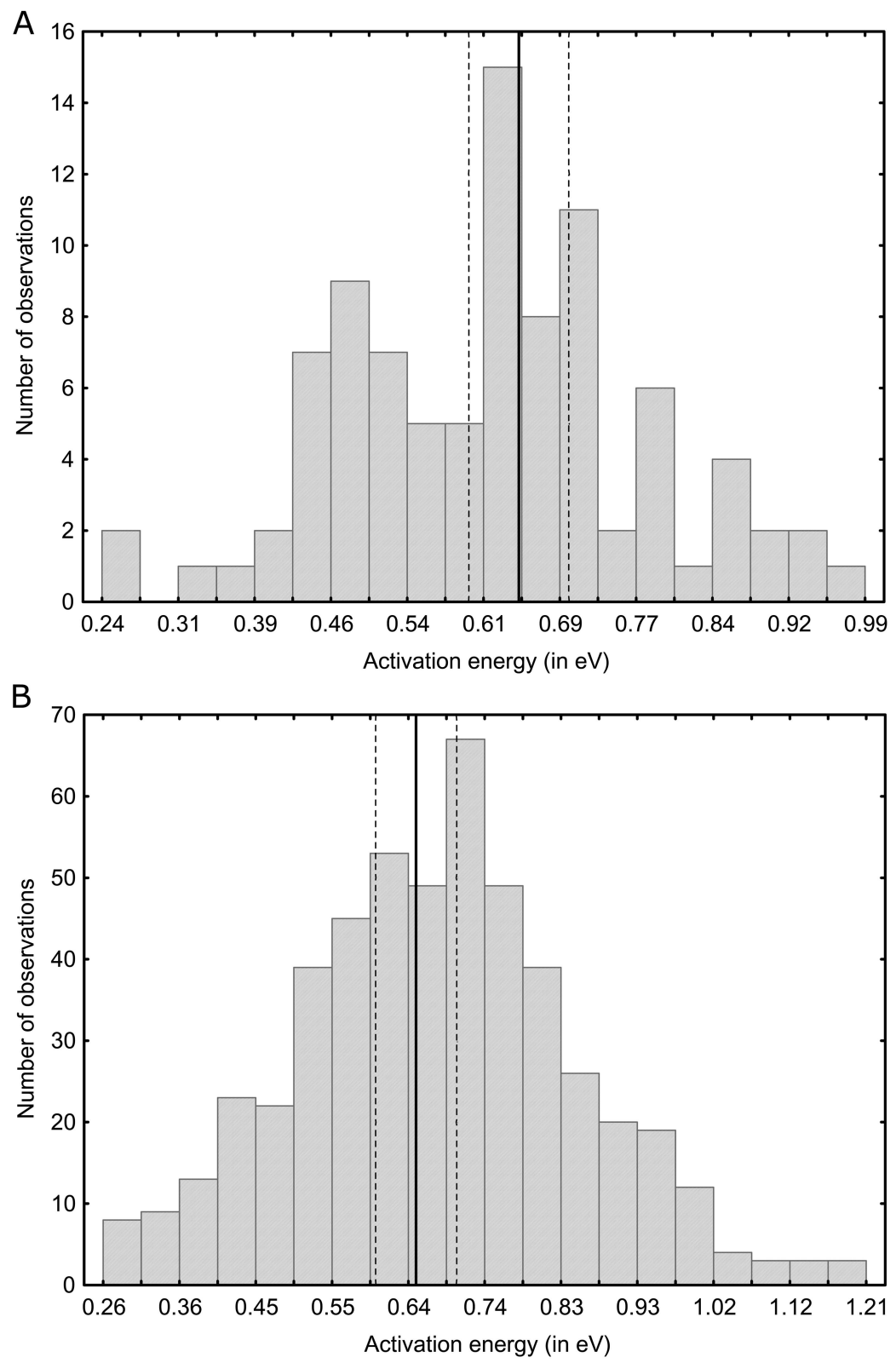

Figure 1: Frequency distribution of the intraspecific activation energies of $(A)$ metabolic rate data and $(B)$ development rate data compared with the predicted range of $0.6-0.7 \mathrm{eV}$. In each case, the solid line shows the predicted mean value of $0.65 \mathrm{eV}$, and the dashed lines show the $0.6-0.7$ eV range.

rate-temperature relationship, the mean activation energy $(0.68 \mathrm{eV})$ was significantly larger $(95 \% \quad \mathrm{CI}=$ $0.662-0.692, t=-3.45, \mathrm{df}=505, P<.001)$ than the proposed value of $0.65 \mathrm{eV}$. However, the mean value still fell within the predicted range of 0.6 and $0.7 \mathrm{eV}$, but only $21 \%$ of the empirical values lay within this range (fig. $1 B$ ).

Significant systematic variation in both rate-temperature relationships was found. Geographic location in the form of hemisphere was retained in the best-fit models for both metabolic (table 1) and development (table 2) rate-temperature relationships, with latitudinal position also being significant for the former. In both cases, the rate-temperature relationships tended to become steeper toward higher latitudes and showed distinct hemispheric differences. In both cases, $\lambda=0$, and therefore no need existed to correct for phylogenetic nonindependence. 
Table 1: Phylogenetic generalized least squares results of the influence of the explanatory variables on the slope of the relationship between metabolic rate $\left(\ln \mu \mathrm{W} / \mathrm{g}^{3 / 4}\right)$ and temperature

\begin{tabular}{lrcrccc}
\hline Predictor & Estimate & SE & \multicolumn{1}{c}{$t$ value } & $P$ & AIC & $\lambda$ \\
\hline Latitude & .0002 & .0001 & 3.3660 & .00114 & -610.59 & 0 \\
Hemisphere & .0141 & .0057 & 2.4680 & .01558 & & \\
Method & .0050 & .0020 & 2.4570 & .01602 & & \\
Wings & .0028 & .0018 & 1.5440 & .12615 & & \\
MAT & -.0003 & .0001 & -2.3300 & .0221 & -604.43 & 0 \\
MAP & .0000 & .0000 & -1.3850 & .1697 & & \\
Hemisphere & -.0032 & .0023 & -1.3900 & .1682 & & \\
Method & .0039 & .0025 & 1.5380 & .1277 & & \\
Wings & .0036 & .0020 & 1.8640 & .0658 & & \\
TWQ & -.0003 & .0001 & -2.1660 & .03307 & -601.66 & 0 \\
Hemisphere & -.0069 & .0021 & -3.3020 & .00139 & & \\
Wings & .0032 & .0019 & 1.6420 & .10414 & & \\
\hline
\end{tabular}

Note: AIC $=$ Akaike Information Criterion value; $\lambda=$ lambda for phylogenetic correlation; MAT = mean annual temperature; MAP $=$ mean annual precipitation; TWQ $=$ temperature of warmest quarter; method $=$ closed- or open-system respirometry; wings = flying or nonflying insects.

In the case of the slopes of the metabolic rate-temperature relationships, virtually all the climatic variables were retained in the best-fit model using MAT, MAP, and their seasonality (table 1). However, none was significant, except in the reduced model, where a negative relationship between slope and MAT was found. When mean values for the warmest quarter were included, only hemisphere was significant, but in the reduced model, both hemisphere and TWQ were significant. In all cases, $\lambda=0$, and therefore no need existed to correct for phylogenetic nonindependence. Thus, it seems that weak latitudinal variation in the slope of the rate-temperature relationship is present, that this is associated with TWQ or MAT, and that the relationship varies between the hemispheres (fig. 2A).

For the slopes of the development rate-temperature relationships, either MAT or temperature seasonality was significant, depending on the model (table 2). Here, $\lambda=0.088$, and in the phylogenetic models, all variables were included, but none were significant. Using TWQ and PWQ, TWQ and hemisphere were always significant, and $\lambda=0$. Thus, the relationships were similar to those found for slopes of the metabolic rate-temperature relationships, except that here temperature seasonality may account for some of the variation and the difference among the hemispheres was in the opposite direction (fig. 2B). The variance explained in the best generalized linear models for the metabolic rate data ranged between $13 \%$ and $21 \%$ and for the development rate models between $2.5 \%$ and $5 \%$.

\section{Interspecific Rate-Temperature Relationships}

In the case of metabolic rate, the range of activation energy values predicted by the MTE did not overlap with the $95 \%$
CIs of the calculated values for the randomly selected values at TWQ and at the median temperature, but it did so in all of the other cases (fig. $3 A$ ). By contrast, the range of values predicted by the MTE did not overlap with the 95\% CIs of the interspecific activation energy for development rate in all cases, except where development rate was interpolated to the MAT (fig. 3B).

On the basis of $95 \%$ CIs, the mean intraspecific activation energy calculated from the slopes of the metabolic rate-temperature relationships did not differ from the interspecific values for activation energy calculated in all six ways, with one exception-the interspecific slope calculated using the values at TWQ (fig. $3 A$ ). In the case of development rate, the $95 \%$ CIs of the mean intraspecific data overlapped only with the CIs for the interspecific value calculated using data at the MAT (fig. $3 B$ ).

\section{Discussion}

According to the MTE, vital rates vary largely as a consequence of body mass and temperature, with residual variation lying largely in the normalization constant $b_{0}$ (Gillooly et al. 2001, 2006; Brown et al. 2004; Enquist et al. 2007a). Moreover, the MTE does not typically predict consistent variation in the form of the body size and temperature components of its fundamental equation, except perhaps in the case of the mass scaling of metabolic rate in mammals (Savage et al. 2004b), which is contentious (Kozłowski and Konarzewski 2004; White and Seymour 2004). Indeed, Clarke $(2004,2006)$ has argued that a substantial difference between the UTD component of the fundamental equation and other explanations for ratetemperature relationships at the whole-organismal level (such as his ETO hypothesis) is that the former posits equivalent slopes or activation energies within and among species, while the latter does not. This idea has been confirmed by the proponents of the MTE (Brown and Sibly 2006), though not consistently so (Gillooly et al. 2006). Nonetheless, this prediction of intra- versus interspecific similarity in slopes of the rate-temperature relationship, as well as predictions of little phylogenetic variation and little consistent, directional environmental variation in the exponents of the fundamental equation of the MTE, provides readily testable predictions of the MTE that concern not just the mean value of the exponents, which might be equally well predicted by a range of models (see discussions in Angilletta and Dunham 2003; Kozłowski et al. 2003a, 2003b; Clarke 2004; Glazier 2005; Chown et al. 2007).

This study showed that the first step in any assessment of the UTD of the MTE, or indeed of any explanations for variation in rate-temperature relationships (e.g., Clarke 2004; Ikemoto 2005; de Jong and van der Have 2008), must be to understand the artifacts that might be asso- 
Table 2: Phylogenetic generalized least squares results of the influence of the explanatory variables on the slope of the relationship between development rate $(\ln 1 / D)$ and temperature

\begin{tabular}{lrccccc}
\hline Predictor & Estimate & SE & \multicolumn{1}{c}{$t$ value } & $P$ & AIC & \multicolumn{1}{c}{$\lambda$} \\
\hline Hemisphere & .0032 & .0014 & 2.2830 & .0230 & $-2,366.20$ & 0 \\
MAT & -.0003 & .0001 & & & $-2,369.69$ & .0884 \\
Temperature seasonality & .0000 & .0000 & & & & \\
Precipitation seasonality & .0000 & .0000 & & & & \\
Hemisphere & .0028 & .0016 & & & & \\
TWQ & -.0003 & .0001 & -2.4880 & .0133 & $-2,370.40$ & 0 \\
Hemisphere & .0032 & .0014 & 2.3210 & .0208 & & \\
\hline
\end{tabular}

Note: AIC = Akaike Information Criterion value; $\lambda=$ lambda for phylogenetic correlation; MAT = mean annual temperature; TWQ $=$ temperature of warmest quarter.

ciated with the data-collection process. Here, it is clear that the method used to acquire metabolic rate data has a pronounced effect on the slope of the rate-temperature relationship and therefore on the activation energy. Indeed, studies that use groups of individuals are likely to conclude that the slope of the relationship is much steeper than it is in reality. The same is true of investigations that use closed versus open respirometry systems (for discussion of methods see Lighton 1991; Chown and Nicolson 2004). It seems most likely that these results are the consequence of the fact that the closed-system method cannot detect movement of individuals as readily as can flow-throughsystem methods (Lighton and Fielden 1995; Chown et al. 2003; Terblanche et al. 2004) and that movement rate increases with increasing temperature (Gilchrist 1996; Deere and Chown 2006). Therefore, rate temperature relationships are likely to be steeper when assessed using closedsystem methods. This effect is likely to be compounded when groups of individuals are used simply by the probability of more individuals being active as temperature increases. This would suggest very steep values for ratetemperature relationships of the grouped animals, which is indeed what was found (app. A). By contrast, little effect of laboratory adaptation or acclimation was found on the slope of the development rate-temperature relationship. In consequence, all studies of rate-temperature relationships must carefully screen the data that are used to avoid the introduction of likely confounding factors or should at least explicitly take them into account in formal analyses. Investigations of the mass-scaling component of the fundamental equation of the MTE have also shown that several confounding factors must be taken into account during empirical assessments thereof (McKechnie and Wolf 2004; Farrell-Gray and Gotelli 2005; White and Seymour 2005; McKechnie et al. 2006; Chown et al. 2007; Terblanche et al. 2007).

Having taken confounding factors into account, this study showed that the mean intraspecific activation energies for both metabolic rate and development rate lay close to the values proposed by the MTE (Gillooly et al. 2001, 2002; Brown et al. 2004) and certainly well within the $0.6-0.7 \mathrm{eV}$ range, although the mean for the latter was significantly larger than the $0.65 \mathrm{eV}$ mean value predicted by the MTE. However, only $21 \%-31 \%$ of the activation energies fell within the $0.6-0.7 \mathrm{eV}$ range. It is possible to interpret these results either as providing support for the MTE or as rejecting the idea, depending, unfortunately, on the perspective adopted. For example, the previously published biochemical activation energies that Gillooly et al. (2001) used to form the basis for their whole-organismal "predictions" varied between 0 and $1.45 \mathrm{eV}$ (see "Introduction"), somewhat larger than the range found in this study (fig. 1). Moreover, Gillooly et al.'s (2001, 2002) later interpretations of their data suggested a range of values in the order of approximately $0.6-0.7 \mathrm{eV}$, which they then argued were predictions of the MTE (Gillooly et al. 2006; Allen and Gillooly 2007). Therefore, it might be argued that the present data support the UTD component of the fundamental equation of the MTE. In this case, though, the reasoning might be considered suspiciously circular. Alternatively, it might be argued that because so few of the intraspecific activation energies lie between 0.6 and 0.7 , the UTD cannot be applied at the intraspecific level, especially because more recent statements by the proponents of the MTE have suggested that the activation energy should be reasonably tightly constrained between 0.6 and $0.7 \mathrm{eV}$ (Brown et al. 2004; Gillooly et al. 2006; Allen and Gillooly 2007). However, because such conclusions might be considered an assessment of the soft UTD hypothesis (i.e., statistical description hypothesis of Clarke 2004) rather than the hard UTD hypothesis intended by Gillooly et al. (2001), it is necessary first to examine the outcomes of the tests of the consistent phylogenetic and environmental variation about these relationships and the differences between the intraspecific and the interspecific activation energies.

Unlike the situation for the scaling exponent of the fundamental equation of the MTE (see Kozłowski et al. 


\section{A}

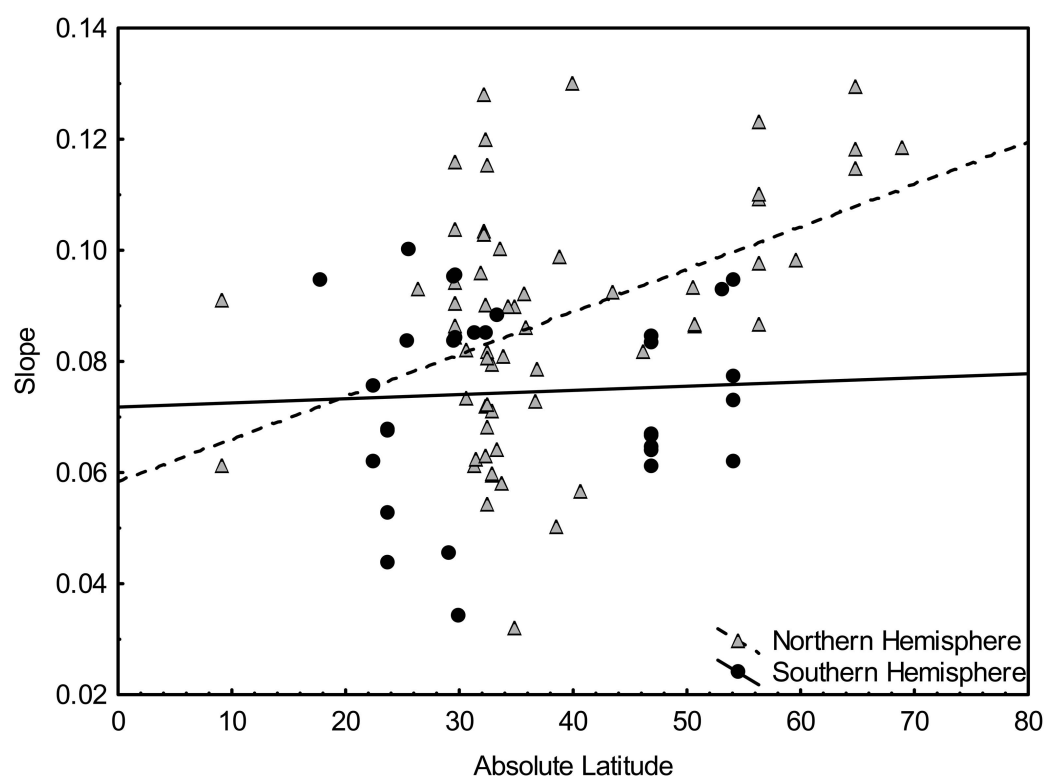

B

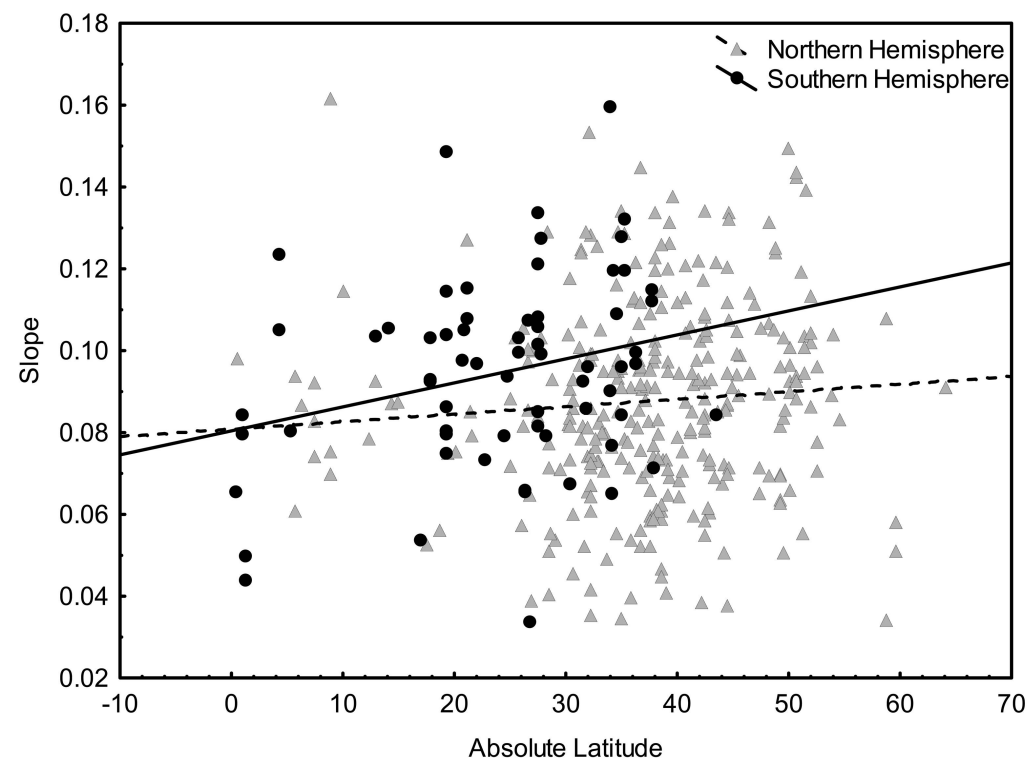

Figure 2: $A$, Slopes of the relationship between metabolic rate $\left(\ln \mu \mathrm{W} / \mathrm{g}^{3 / 4}\right)$ and temperature plotted against absolute latitude. For the Northern Hemisphere, the relationship between latitude and the slope of the relationship was significant $\left(R^{2}=0.185, P<.05\right)$, while for the Southern Hemisphere, the relationship was not significant $\left(R^{2}=0.003, P>.05\right)$. B, Slopes of the relationship between development rate $(\ln 1 / D)$ and temperature plotted against absolute latitude. For the Northern Hemisphere, the development rate-temperature relationship was not significant $\left(R^{2}=0.006\right.$, $P>.05)$, while for the Southern Hemisphere, the relationship was significant $\left(R^{2}=0.068, P<.05\right)$.

2003a, 2003b; White and Seymour 2003; Chown et al. 2007), little of the variation in the slopes of the ratetemperature relationships was accounted for by phylogenetic relatedness. By contrast, for the metabolic rate-temperature data, at least $20 \%$ of the variance was a result of consistent variation with latitude and hemisphere, mostly as a consequence of differences in the extent of seasonality among latitudes and hemispheres. Such consistent variation is larger than that estimated by Gillooly et al. (2006) from a previous investigation (Addo-Bediako et al. 2002) 


\section{A}

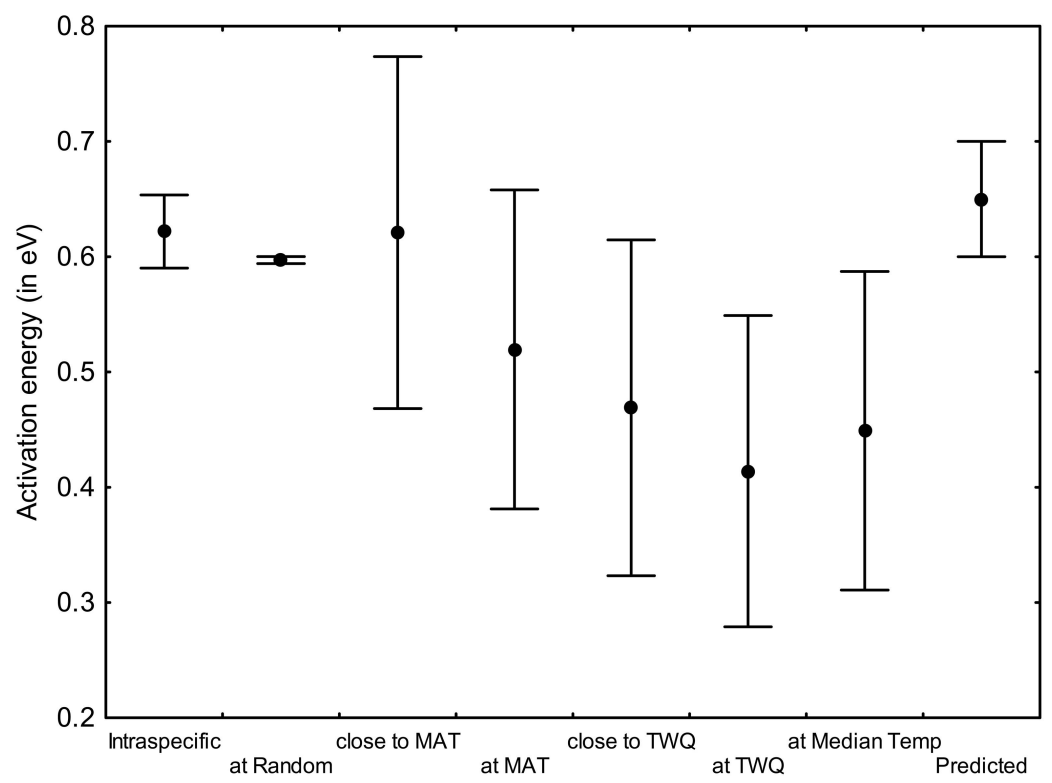

B

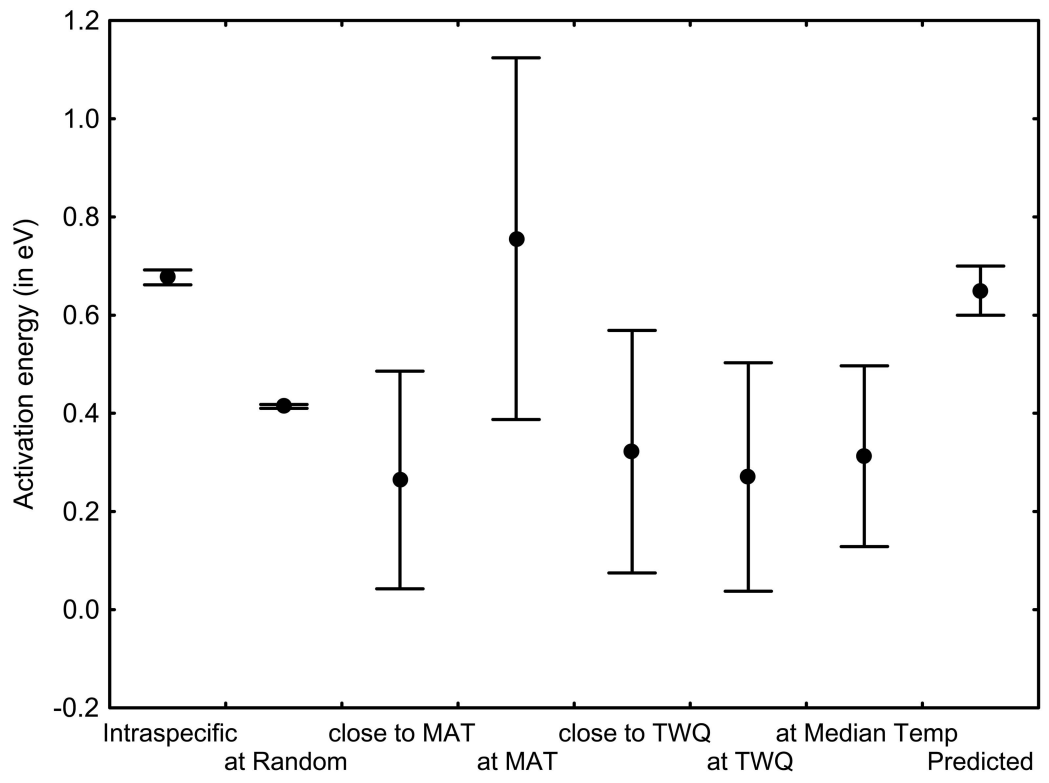

Figure 3: Mean and 95\% confidence intervals of $(A)$ the intraspecific activation energies for metabolic rate compared with the mean interspecific activation energy for metabolic rate $( \pm 95 \% \mathrm{CI})$ calculated in six different ways and $(B)$ the intraspecific activation energies for development rate compared with the mean interspecific activation energy for development rate $( \pm 95 \% \mathrm{CI})$ calculated in six different ways. In each case, the predicted range of $0.6-0.7 \mathrm{eV}$ is also shown. MAT = mean annual temperature; TWQ $=$ temperature of the warmest quarter.

of a smaller data set and is not predicted by the MTE. Moreover, it is consistent with the outcome of this previous investigation, which concluded that differences in climate and the opportunities for behavioral thermoregulation might account for the marked difference in the change of slope of the metabolic rate-temperature relationship with hemisphere.

In the case of development rate, much less of the var- 
iation in the slope of the relationships was explained by environmental variables. Moreover, environmental influences were more complicated than in the case of metabolic rate. However, consistent variation in the relationships was found, although for the differences among hemispheres, it was in a direction different from that found for metabolic rate. Why this might be the case is not entirely clear. Indeed, several previous studies have suggested that species from warm areas should in fact have steeper slopes than those from temperate areas and that this is a consequence of trade-offs between the lower development threshold (LDT), which declines strongly with latitude, and the sum of effective temperatures (SET; 1/slope of the linear ratetemperature relationship; e.g., Li 1998; Ikemoto and Takai 2000; Ikemoto 2005; Trudgill et al. 2005). However, although declines in LDT are commonly found, variation among areas in SET is less consistent (Honěk 1996a). In addition, because LDT $(=-a / b$, from the linear regression, rate $=a+b \times$ temperature $)$ and SET $(=1 / b$, from the previous regression) both include the slope of the ratetemperature relationship in their calculation (i.e., the LDT vs. the SET relationship takes the form $Y / X$ vs. $X$; see, e.g., Jarošík et al. 2002), a strong negative relationship between them should, in fact, serve as the null expectation (see discussion in Brett 2004). In consequence, the current findings are of considerable interest. It seems likely that they have to do with the range of environments encountered by all developmental stages (see Honěk 1996a, 1996b; Chown et al. 2002), the way in which energy is partitioned between the costs of maintenance and the costs of growth, and the way in which rate-temperature relationships and body size might interact (for further discussion see Honěk 1996a, 1996b; de Jong and van der Have 2008; Dixon et al. 2009). Nonetheless, it is clear that for both development rate and metabolic rate, consistent variation in the form of the rate-temperature relationship was present.

The slopes of the interspecific development rate-temperature relationships were typically shallower than the mean slopes of the intraspecific relationships, although the range of the latter encompassed the former. Likewise, the interspecific activation energy value tended to be lower than the $0.6-0.7 \mathrm{eV}$ proposed by the MTE, irrespective of the method used to calculate it. For metabolic rate, the converse appeared to be the case. Moreover, at least half of the calculated interspecific activation energies had 95\% CIs that overlapped with the predicted $0.6-0.7 \mathrm{eV}$ value. Therefore, the interspecific and intraspecific activation energies certainly did differ and often in the direction predicted by Clarke $(2003,2004,2006)$; that is, the intraspecific slopes should be steeper than the interspecific ones. However, this was dependent to some extent on the environmental temperature at which the insect was thought to live its adult life or its entire development.
Given that so many insect species in more temperate latitudes undergo some form of inactivity, quiescence, or diapause during the winter months (Leather et al. 1993; Convey 1996; Danks 2002), it seems reasonable to suppose that TWQ is a better predictor than MAT of the temperatures at which the animals find themselves growing and (in adults) metabolizing (Hodkinson 2003). In turn, such an assumption presumes that all of the species examined are largely active in summer, that Stevenson screen temperatures are a reasonable proxy for microclimates experienced and selected by insects (see Chown et al. 2003), and that the evolution of responses to deal with environmental extremes at other times of the year in no way constrains the temperature sensitivity of growth, development, and metabolism to a certain range of values. Most of the studies used here did not provide explicit information on the activity times of the species they examined or the likely microclimates they inhabited. Therefore, it is difficult to determine the extent to which these assumptions are correct. Although it is well known that insects actively regulate their body temperatures in a wide variety of ways (reviewed in Heinrich 1993; Chown and Nicolson 2004) and that microhabitat selection can influence experienced ambient temperature considerably (Leather et al. 1993; Addo-Bediako et al. 2000; Pincebourde and Casas $2006 a, 2006 b$ ), the extent to which this is likely affects macrophysiological investigations at a scale that has not been thoroughly explored (see discussions in Chown et al. 2003; Hodkinson 2003; Chown and Terblanche 2007). Similarly, it is difficult to determine what the likely influence is of biochemical strategies to avoid environmental stress on metabolism and ontogeny generally. While some studies suggest that the stress phenotype results from considerable biochemical resculpting (e.g., Zachariassen 1985; Bale 2002; Storey 2002; Storey and Storey 2004), others emphasize the tight linkage between stressful and nonstressful conditions (Voituron et al. 2002; Makarieva et al. 2006). Therefore, it is not clear which temperature is the "right" one to use when conducting interspecific examinations of rate-temperature dependence of the kind originally proposed by Gillooly et al. (2001). Clearly, the choice can make a substantive difference to the outcome of a comparison of interspecific and intraspecific data, although in turn this depends on the trait under investigation. Future studies clearly need to be specific about the temperatures used, and some investigation of what the most appropriate temperatures are is required.

Bearing in mind these issues and the original questions we posed, we conclude the following: the hard version of the UTD hypothesis does not appear to be fully supported by the data for insect metabolic and development rates. The large majority of the intraspecific values for activation energy lay outside the $0.6-0.7 \mathrm{eV}$ range, as did many of 
the estimates of interspecific activation energy. Moreover, the inter- and intraspecific values differed for development rate and at least in one case for metabolic rate, and environmental variation in a consistent direction (i.e., not at random with respect to the central tendency) was found in the rate-temperature relationships. Therefore, the empirical data for insects provide limited support for the temperature component of the fundamental equation of the MTE. Nonetheless, that some support has been found for its ancillary predictions for insects might suggest otherwise. For example, Charnov and Gillooly (2003) predicted that temperature range for development should be a constant $\left(20^{\circ} \mathrm{C}\right)$, with the boundaries shifting from warm to cold areas. Dixon et al. (2009) provided support for this idea, using a database of 66 values of upper and lower thermal limits to development of insects, which had a mean of $19.8^{\circ} \mathrm{C}$ and a range of $13^{\circ}-29^{\circ} \mathrm{C}$. Our data often did not include estimates of upper thermal limits to development. However, Nietshcke et al. (2007) provide such information for 96 insect species. Preliminary analysis thereof shows that the thermal range among the species varies from $7^{\circ}$ to $34^{\circ} \mathrm{C}$, with a mean of $22.6^{\circ} \mathrm{C}$ and more than half of the data lying outside the CIs given by Dixon et al. (2009) - that is, an outcome similar to the one we found here for activation energies.

In consequence, alternative hypotheses, such as the ETO hypothesis proposed by Clarke (2004), need to be explored. Indeed, this is only one of a range of models that seek to explore how various biological rates should vary with temperature and how such variation evolves. For development rates, the Sharpe-Schoolfield model (see Schoolfield et al. 1981) has perhaps attracted the most attention, and it has been argued that selection may act on any of the model's parameters (de Jong and van der Have 2008). However, some of the downstream uses of this approach, especially regarding the relationships between LDT and SET (e.g., Jarošík et al. 2002; Ikemoto 2005; Trudgill et al. 2005), and the significance thereof in the context of body size evolution (see de Jong and van der Have 2008; Chown and Gaston 2009) remain in need of more careful investigation. Given the ecological, evolutionary, and applied biological significance of ratetemperature relationships and the diversity of insects as a model group on which to investigate them, further work in this area is bound to be important and obviously much needed.

\section{Acknowledgments}

We thank S. Clusella-Trullas, M. Zalucki, and an anonymous reviewer for an extensive and helpful set of comments on a previous version of the manuscript. We are especially grateful to the anonymous reviewer for a his- tory of electron volt values in the context of the MTE. We thank R. Duncan for R code to perform the PGLS analysis. This work was supported partially by National Research Foundation grant FA2004032000006.

\section{APPENDIX A}

\section{Methodological Effects on the Slopes of the Rate-Temperature Relationships}

The effects of grouping, respirometry method, and wing status on the slope of the metabolic rate-temperature relationship and the effect of field-collected or laboratorycolony status were investigated here.

\section{Approach}

It is widely known that activity of individuals during trials may confound estimates of standard metabolic rate (Chown and Nicolson 2004). Closed-system respirometry often fails to account for activity and usually results in higher estimates of metabolic rate than real-time, open (flow-through), or similar methods (Lighton and Fielden 1995). It was reasoned that higher temperatures would result in a higher probability of activity and therefore that for closed-system methods, slopes of the rate-temperature relationship would be steeper. Likewise, it was reasoned that where individuals were measured in groups, rather than individually, steeper rate-temperature slopes would also be found, owing to increasing opportunities for disturbance of the whole group at higher temperatures or a greater proportion of the group being active. Previous studies have also noted that flying insects have metabolic rates higher than those of nonvolant ones (Reinhold 1999), but no investigations of consistent variation in ratetemperature relationships have been undertaken. In a similar vein, the difference between field- and laboratoryacclimated animals in the development rate analyses was investigated because laboratory adaptation/acclimation has been commonly reported (Chown and Terblanche 2007). In all cases we used generalized linear models, assuming a normal distribution with a log-link function, to examine differences among the groups defined above.

\section{Results}

The mean slope of the metabolic rate-temperature relationship was significantly higher in studies where animals were examined in groups (as activation energy; $0.76 \pm$ $0.20 \mathrm{eV}[\mathrm{SD}])$ than where single individuals were used $\left(0.62 \pm 0.15 \mathrm{eV} ; \chi^{2}=12.10, \mathrm{df}=127, P<.001\right)$. After excluding studies that examined groups of individuals, the database contained 91 species in eight orders and 22 fam- 
ilies, of which 30 species were collected in the Southern Hemisphere and 61 in the Northern Hemisphere. Respirometry method likewise had an effect on the slopes of the rate-temperature relationships, with open-system methods resulting in shallower slope estimates and activation energies than closed-system methods (0.65 \pm 0.15 and $0.56 \pm 0.14 \mathrm{eV}$, respectively; $\chi^{2}=8.30, \mathrm{df}=$ $89, P<.005)$. This distinction was therefore included as an independent categorical predictor variable in subsequent analyses. The ability to fly had no significant effect on the estimated slope of the metabolic rate-temperature relationships $\left(\chi^{2}=2.97\right.$, df $\left.=89, P>.05\right)$.

Of the 506 species, data for 377 species were from fieldcollected animals, and data for 129 species were from laboratory-reared animals. No significant difference was found in the slopes of the development rate-temperature relationship between field-collected and laboratory-reared animals (field: $0.67 \pm 0.18 \mathrm{eV}$; laboratory: $0.69 \pm 0.17 \mathrm{eV}$; $\left.\chi^{2}=0.70, \mathrm{df}=504, P>.05\right)$. Of the field-collected animals, 67 species were collected in the Southern Hemisphere and 310 in the Northern Hemisphere.

\section{APPENDIX B}

\section{Calculation of the Interspecific Rate-Temperature Relationships}

Six approaches were adopted for calculating the interspecific rate-temperature relationships. (1) For each species a metabolic or development rate measurement, together with the specific experimental temperature, was selected at random from the available data. These values were then used to determine an interspecific slope. This process was repeated 1,000 times. The mean slope, with its corresponding confidence intervals of this randomization, was used for further investigation. (2) The slopes were calculated such that a metabolic or development rate value at the experimental temperature closest to the mean annual temperature (MAT) for each species was used as the dependent variable and the temperature closest to the MAT for each species was used as the independent variable. (3) Metabolic or development rate at the MAT for each species was determined by interpolation of the intraspecific ratetemperature relationship to provide the independent variable, and MAT was used as the independent variable. (4) Same procedure as in 2 but with temperature of the warmest quarter (TWQ). (5) Same procedure as in 3 but with TWQ. (6) For each species the median experimental temperature was selected. However, if no median was available, because of an even number of experimental temperatures, the temperature closest to the MAT was selected.

\section{Literature Cited}

Addo-Bediako, A., S. L. Chown, and K. J. Gaston. 2000. Thermal tolerance, climatic variability and latitude. Proceedings of the Royal Society B: Biological Sciences 267:739-745.

- 2002. Metabolic cold adaptation in insects: a large-scale perspective. Functional Ecology 16:332-338.

Algar, A. C., J. T. Kerr, and D. J. Currie. 2007. A test of metabolic theory as the mechanism underlying broad-scale species-richness gradients. Global Ecology and Biogeography 16:170-178.

Allen, A. P., and J. F. Gillooly. 2006. Assessing latitudinal gradients in speciation rates and biodiversity at the global scale. Ecology Letters 9:947-954.

2007. The mechanistic basis of the metabolic theory of ecology. Oikos 116:1073-1077.

Allen, A. P., J. H. Brown, and J. F. Gillooly. 2002. Global biodiversity, biochemical kinetics, and the energetic-equivalence rule. Science 297:1545-1548.

Allen, A. P., J. F. Gillooly, V. M. Savage, and J. H. Brown. 2006. Kinetic effects of temperature on rates of genetic divergence and speciation. Proceedings of the National Academy of Sciences of the USA 103:9130-9135.

Angilletta, M. J. 2006. Estimating and comparing thermal performance curves. Journal of Thermal Biology 31:541-545.

- 2009. Thermal adaptation: a theoretical and empirical synthesis. Oxford University Press, Oxford.

Angilletta, M. J., and A. E. Dunham. 2003. The temperature-size rule in ectotherms: simple evolutionary explanations may not be general. American Naturalist 162:332-342.

Bale, J. S. 2002. Insects and low temperatures: from molecular biology to distributions and abundance. Philosophical Transactions of the Royal Society B: Biological Sciences 357:849-861.

Birkemoe, T., and H. P. Leinaas. 2000. Effects of temperature on the development of an arctic Collembola (Hypogastrura tullbergi). Functional Ecology 14:693-700.

Brett, M. T. 2004. When is a correlation between non-independent variables "suspicious"? Oikos 105:647-656.

Brown, J. H., and R. M. Sibly. 2006. Life-history evolution under a production constraint. Proceedings of the National Academy of Sciences of the USA 103:17595-17599.

Brown, J. H., J. F. Gillooly, A. P. Allen, V. M. Savage, and G. B. West. 2004. Toward a metabolic theory of ecology. Ecology 85:17711789.

Burnham, K. P., and D. R. Anderson. 2002. Model selection and multimodel inference: a practical information-theoretic approach. Springer, New York.

Campbell, A., B. D. Frazer, N. Gilbert, A. P. Gutierrez, and M. Mackauer. 1974. Temperature requirements of some aphids and their parasites. Journal of Applied Ecology 11:431-438.

Charnov, E. L., and J. F. Gillooly. 2003. Thermal time: body size, food quality and the $10^{\circ} \mathrm{C}$ rule. Evolutionary Ecology Research 5: $43-51$.

Chown, S. L. 1997. Thermal sensitivity of oxygen uptake of Diptera from sub-Antarctic South Georgia and Marion Island. Polar Biology 17:81-86.

Chown, S. L., and K. J. Gaston. 1999. Exploring links between physiology and ecology at macro-scales: the role of respiratory metabolism in insects. Biological Reviews 74:87-120.

- 2009. Body size variation in insects: a macroecological perspective. Biological Reviews (forthcoming). 
Chown, S. L., and S. W. Nicolson. 2004. Insect physiological ecology: mechanisms and patterns. Oxford University Press, Oxford.

Chown, S. L., and J. S. Terblanche. 2007. Physiological diversity in insects: ecological and evolutionary contexts. Advances in Insect Physiology 33:50-152.

Chown, S. L., A. Addo-Bediako, and K. J. Gaston. 2002. Physiological variation in insects: large-scale patterns and their implications. Comparative Biochemistry and Physiology B 131:587-602.

. 2003. Physiological diversity: listening to the large-scale signal. Functional Ecology 17:568-572.

Chown, S. L., E. Marais, J. S. Terblanche, C. J. Klok, J. R. B. Lighton, and T. M. Blackburn. 2007. Scaling of insect metabolic rate is inconsistent with the nutrient supply network model. Functional Ecology 21:282-290.

Clarke, A. 1993. Seasonal acclimatization and latitudinal compensation in metabolism: do they exist? Functional Ecology 7:139149.

2003. Costs and consequences of evolutionary temperature adaptation. Trends in Ecology \& Evolution 18:573-581.

- 2004. Is there a universal temperature dependence of metabolism? Functional Ecology 18:252-256.

- 2006. Temperature and the metabolic theory of ecology. Functional Ecology 20:405-412.

Clarke, A., and N. M. Johnston. 1999. Scaling of metabolic rate with body mass and temperature in teleost fish. Journal of Animal Ecology 68:893-905.

Convey, P. 1996. The influence of environmental characteristics on life history attributes of Antarctic terrestrial biota. Biological Reviews 71:191-225.

Cossins, A. R., and K. Bowler. 1987. Temperature biology of animals. Chapman \& Hall, London.

Danks, H. V. 2002. The range of insect dormancy responses. European Journal of Entomology 99:127-142.

Deere, J. A., and S. L. Chown. 2006. Testing the beneficial acclimation hypothesis and its alternatives for locomotor performance. American Naturalist 168:630-644.

de Jong, G., and T. M. van der Have. 2008. Temperature dependence of development rate, growth rate and size: from biophysics to adaptation. Pages 461-526 in D. W. Whitman and T. N. Ananthakrishnan, eds. Phenotypic plasticity of insects: mechanisms and consequence. Science, Enfield, NH.

Deutsch, C. A., J. J. Tewksbury, R. B. Huey, K. S. Sheldon, C. K. Ghalambor, D. C. Haak, and P. R. Martin. 2008. Impacts of climate warming on terrestrial ectotherms across latitude. Proceedings of the National Academy of Sciences of the USA 105:6668-6672.

Dixon, A. F. G., A. Honěk, P. Keil, M. A. A. Kotela, A. L. Šizling, and V. Jarošík. 2009. Relationship between the minimum and maximum temperature thresholds for development in insects. Functional Ecology 23:257-264.

Enquist, B. J., A. J. Kerkhoff, T. E. Huxman, and E. P. Economo. 2007a. Adaptive differences in plant physiology and ecosystem paradoxes: insights from metabolic scaling theory. Global Change Biology 13:591-609.

Enquist, B. J., A. J. Kerkhoff, S. C. Stark, N. G. Swenson, M. C. McCarthy, and C. A. Price. 2007b. A general integrative model for scaling plant growth, carbon flux, and functional trait spectra. Nature 449:218-222.

Ernest, S. K. M., B. J. Enquist, J. H. Brown, E. L. Charnov, J. F. Gillooly, V. Savage, E. P. White, et al. 2003. Thermodynamic and metabolic effects on the scaling of production and population energy use. Ecology Letters 6:990-995.

Farrell-Gray, C. C., and N. J. Gotelli. 2005. Allometric exponents support a 3/4-power scaling law. Ecology 86:2083-2087.

Frazier, M. R., R. B. Huey, and D. Berrigan. 2006. Thermodynamics constrains the evolution of insect population growth rates: "warmer is better." American Naturalist 168:512-520.

Gaston, K. J., S. L. Chown, and K. L. Evans. 2008. Ecogeographical rules: elements of a synthesis. Journal of Biogeography 35:483500.

Gilchrist, G. W. 1996. A quantitative genetic analysis of thermal sensitivity in the locomotor performance curve of Aphidius ervi. Evolution 50:1560-1572.

Gillooly, J. F., J. H. Brown, G. B. West, V. M. Savage, and E. L. Charnov. 2001. Effects of size and temperature on metabolic rate. Science 293:2248-2251.

Gillooly, J. F., E. L. Charnov, G. B. West, V. M. Savage, and J. H Brown. 2002. Effects of size and temperature on developmental time. Nature 417:70-73.

Gillooly, J. F., A. P. Allen, G. B. West, and J. H. Brown. 2005. The rate of DNA evolution: effects of body size and temperature on the molecular clock. Proceedings of the National Academy of Sciences of the USA 102:140-145.

Gillooly, J. F., A. P. Allen, V. M. Savage, E. L. Charnov, G. B. West, and J. H. Brown. 2006. Response to Clarke and Fraser: effects of temperature on metabolic rate. Functional Ecology 20:400-404.

Glazier, D. S. 2005. Beyond the "3/4-power law": variation in the intra- and interspecific scaling of metabolic rate in animals. Biological Reviews 80:611-662.

Grafen, A. 1989. The phylogenetic regression. Philosophical Transactions of the Royal Society B: Biological Sciences 326:119-157.

Halsey, L. G., P. J. Butler, and T. M. Blackburn. 2006. A phylogenetic analysis of the allometry of diving. American Naturalist 167:276287.

Hawkins, B. A., F. S. Albuquerque, M. B. Araújo, J. Beck, L. M. Bini, F. J. Cabrero-Sañudo, I. Castro-Parga, et al. 2007. A global evaluation of metabolic theory as an explanation for terrestrial species richness gradients. Ecology 88:1877-1888.

Hawksworth, D. L., and M. T. Kalin-Arroyo. 1995. Magnitude and distribution of biodiversity. Pages 107-191 in V. H. Heywood and R. T. Watson, eds. Global biodiversity assessment. Cambridge University Press, New York.

Heinrich, B. 1993. The hot-blooded insects: strategies and mechanisms of thermoregulation. Springer, Berlin.

Hijmans, R. J., S. E. Cameron, J. L. Parra, P. G. Jones, and A. Jarvis. 2005. Very high resolution interpolated climate surfaces for global land areas. International Journal of Climatology 25:1965-1978.

Hodkinson, I. D. 2003. Metabolic cold adaptation in arthropods: a smaller-scale perspective. Functional Ecology 17:562-567.

Honěk, A. 1996a. Geographical variation in thermal requirements for insect development. European Journal of Entomology 93:303312 .

-1996b. The relationship between thermal constants for insect development: a verification. Acta Societatis Zoologicae Bohemicae 60:115-152.

Honěk, A., and F. Kocourek. 1990. Temperature and development time in insects: a general relationship between thermal constants. Zoologische Jahrbücher Abteilung für Systematik und Ökologie der Tiere 117:401-439.

Huey, R. B., and R. D. Stevenson. 1979. Integrating thermal physi- 
ology and ecology of ectotherms: a discussion of approaches. American Zoologist 19:357-366.

Huey, R. B., C. A. Deutsch, J. J. Tewksbury, L. J. Vitt, P. E. Hertz, H. J. Álvarez Pérez, and T. Garland Jr. 2009. Why tropical forest lizards are vulnerable to warming. Proceedings of the Royal Society B: Biological Sciences 276:1939-1948, doi:10.1098/rspb.2008.1957. Ikemoto, T. 2005. Intrinsic optimum temperature for development of insects and mites. Environmental Entomology 34:1377-1387.

Ikemoto, T., and K. Takai. 2000. A new linearized formula for the law of total effective temperature and the evaluation of line-fitting methods with both variables subject to error. Environmental Entomology 29:671-682.

Jarošík, V., A. Honěk, and A. F. G. Dixon. 2002. Developmental rate isomorphy in insects and mites. American Naturalist 160:497-510.

Johnson, J. B., and K. S. Omland. 2004. Model selection in ecology and evolution. Trends in Ecology \& Evolution 19:101-108.

Kontodimas, D. C., P. A. Eliopoulos, G. J. Stathas, and L. P. Economou. 2004. Comparative temperature-dependent development of Nephus includens (Kirsch) and Nephus bisignatus (Boheman) (Coleoptera: Coccinellidae) preying on Planococcus citri (Risso) (Homoptera: Pseudococcidae): evaluation of a linear model and various nonlinear models using specific criteria. Environmental Entomology 33:1-11.

Kozłowski, J., and M. Konarzewski. 2004. Is West, Brown and Enquist's model of allometric scaling mathematically correct and biologically relevant? Functional Ecology 18:283-289.

Kozłowski, J., M. Konarzewski, and A. T. Gawelczyk. 2003a. Cell size as a link between noncoding DNA and metabolic rate scaling. Proceedings of the National Academy of Sciences of the USA 100: 14080-14085.

- 2003b. Intraspecific body size optimization produces interspecific allometries. Pages 299-320 in T. M. Blackburn and K. J. Gaston, eds. Macroecology: concepts and consequences. Blackwell Science, Oxford.

Kozłowski, J., M. Czarnoleski, and M. Dańko. 2004. Can optimal resource allocation models explain why ectotherms grow larger in cold? Integrative and Comparative Biology 44:480-493.

Lamb, R. J. 1992. Developmental rate of Acyrthosiphon pisum (Homoptera: Aphididae) at low temperatures: implications for estimating rate parameters for insects. Environmental Entomology 21: $10-19$.

Lawton, J. H. 1999. Are there general laws in ecology? Oikos 84:177192.

Leather, S. R., J. S. Bale, and K. F. A. Walters. 1993. The ecology of insect overwintering. Cambridge University Press, Cambridge.

Li, D. 1998. A linear model for description of the relationship between the lower development threshold and thermal constant in spiders (Araneae: Arachnida). Journal of Thermal Biology 23:23-30.

Lighton, J. R. B. 1991. Insects: measurements. Pages 201-208 in P. A. Payne, ed. Concise encyclopedia on biological and biomedical measurement systems. Pergamon, Oxford.

Lighton, J. R. B., and L. J. Fielden. 1995. Mass scaling of standard metabolism in ticks: a valid case of low metabolic rates in sit-andwait strategists. Physiological Zoology 68:43-62.

Makarieva, A. M., V. G. Gorshkov, and B.-L. Li. 2004. Ontogenetic growth: models and theory. Ecological Modelling 176:15-26.

Makarieva, A. M., V. G. Gorshkov, B.-L. Li, and S. L. Chown. 2006. Size- and temperature-independence of minimum life-supporting metabolic rates. Functional Ecology 20:83-96.

Martins, E. P., and T. F. Hansen. 1997. Phylogenies and the com- parative method: a general approach to incorporating phylogenetic information into the analysis of interspecific data. American Naturalist 149:646-667.

Mayr, E. 1956. Geographical character gradients and climatic adaptation. Evolution 10:105-108.

McArdle, B. H. 1988. The structural relationship: regression in biology. Canadian Journal of Zoology 66:2329-2339.

McCullagh, P., and J. A. Nelder. 1989. Generalized linear models. Chapman \& Hall, London.

McKechnie, A. E., and B. O. Wolf. 2004. The allometry of avian basal metabolic rate: good predictions need good data. Physiological and Biochemical Zoology 77:502-521.

McKechnie, A. E., R. P. Freckleton, and W. Jetz. 2006. Phenotypic plasticity in the scaling of avian basal metabolic rate. Proceedings of the Royal Society B: Biological Sciences 273:931-937.

McLeese, J. M., and J. G. Eales. 1996. 3,5,3'-triiodo-L-thyronine and L-thyroxine uptake into red blood cells of rainbow trout, Oncorhynchus mykiss. General and Comparative Endocrinology 102:4755.

Nietshcke, B. S., R. D. Magarey, D. M. Borchert, D. C. Calvin, and E. Jones. 2007. A developmental database to support insect phenology models. Crop Protection 26:1444-1448.

O’Connor, M. P., S. J. Kemp, S. J. Agosta, F. Hansen, A. E. Sieg, B. P. Wallace, J. N. McNair, and A. E. Dunham. 2007. Reconsidering the mechanistic basis of the metabolic theory of ecology. Oikos 116:1058-1072.

Pagel, M. 1999. Inferring the historical patterns of biological evolution. Nature 401:877-884.

Pincebourde, S., and J. Casas. 2006a. Leaf miner-induced changes in leaf transmittance cause variations in insect respiration rates. Journal of Insect Physiology 52:194-201.

- 2006b. Multitrophic biophysical budgets: thermal ecology of an intimate herbivore insect-plant interaction. Ecological Monographs 76:175-194.

Raven, J. A., and R. J. Geider. 1988. Temperature and algal growth. New Phytologist 110:441-461.

Reinhold, K. 1999. Energetically costly behaviour and the evolution of resting metabolic rate in insects. Functional Ecology 13:217224.

Ricklefs, R. E. 2003. Is rate of ontogenetic growth constrained by resource supply or tissue growth potential? a comment on West et al.'s model. Functional Ecology 17:384-393.

Rohlf, F. J. 2001. Comparative methods for the analysis of continuous variables: geometric interpretations. Evolution 55:2143-2160.

Savage, V. M., J. F. Gillooly, J. H. Brown, G. B. West, and E. L. Charnov. 2004a. Effects of body size and temperature on population growth. American Naturalist 163:429-441.

Savage, V. M., J. F. Gillooly, W. H. Woodruff, G. B. West, A. P. Allen, B. J. Enquist, and J. H. Brown. 2004b. The predominance of quarter-power scaling in biology. Functional Ecology 18:257-282.

Schoolfield, R. M., P. J. H. Sharpe, and C. E. Magnuson. 1981. Nonlinear regression of biological temperature-dependent rate models based on absolute reaction-rate theory. Journal of Theoretical Biology 88:719-731.

Sharpe, P. J. H., and D. W. DeMichele. 1977. Reaction kinetics of poikilotherm development. Journal of Theoretical Biology 64:649670.

Sømme, L., and W. Block. 1991. Adaptations to alpine and polar environments. Pages 318-359 in R. E. Lee and D. L. Denlinger, eds. Insects at low temperature. Chapman \& Hall, London. 
Storey, K. B. 2002. Life in the slow lane: molecular mechanisms of estivation. Comparative Biochemistry and Physiology A 133:733754.

Storey, K. B., and J. M. Storey. 2004. Metabolic rate depression in animals: transcriptional and translational controls. Biological Reviews 79:207-233.

Terblanche, J. S., C. J. Klok, and S. L. Chown. 2004. Metabolic rate variation in Glossina pallidipes (Diptera: Glossinidae): gender, ageing and repeatability. Journal of Insect Physiology 50:419-428.

Terblanche, J. S., C. Janion, and S. L. Chown. 2007. Variation in scorpion metabolic rate and rate-temperature relationships: implications for the fundamental equation of the metabolic theory of ecology. Journal of Evolutionary Biology 20:1602-1612.

Thomas, J. A., J. J. Welch, M. Woolfit, and L. Bromham. 2006. There is no universal molecular clock for invertebrates, but rate variation does not scale with body size. Proceedings of the National Academy of Sciences of the USA 103:7366-7371.

Trudgill, D. L., A. Honěk, and N. M. van Straalen. 2005. Thermal time: concepts and utility. Annals of Applied Biology 146:1-14.

Vetter, R. A. H. 1995. Ecophysiological studies on citrate-synthase. I. Enzyme regulation of selected crustaceans with regard to temperature adaptation. Journal of Comparative Physiology B 165: $45-55$.

Voituron, Y., N. Mouquet, C. de Mazancourt, and J. Clobert. 2002. To freeze or not to freeze? an evolutionary perspective on the coldhardiness strategies of overwintering ectotherms. American Naturalist 160:255-270.

West, G. B., and J. H. Brown. 2005. The origin of allometric scaling laws in biology from genomes to ecosystems: towards a quanti- tative unifying theory of biological structure and organization. Journal of Experimental Biology 208:1575-1592.

West, G. B., J. H. Brown, and B. J. Enquist. 1997. A general model for the origin of allometric scaling laws in biology. Science 276: $122-126$.

. 2001. A general model for ontogenetic growth. Nature 413: $628-631$

. 2004. Growth models based on first principles or phenomenology? Functional Ecology 18:188-196.

White, C. R., and R. S. Seymour. 2003. Mammalian basal metabolic rate is proportional to body mass ${ }^{2 / 3}$. Proceedings of the National Academy of Sciences of the USA 100:4046-4049.

. 2004. Does basal metabolic rate contain a useful signal? mammalian BMR allometry and correlations with a selection of physiological, ecological, and life-history variables. Physiological and Biochemical Zoology 77:929-941.

. 2005. Sample size and mass range effects on the allometric exponent of basal metabolic rate. Comparative Biochemistry and Physiology A 142:74-78.

Yamahira, K., M. Kawajiri, K. Takeshi, and T. Irie. 2007. Inter- and intrapopulation variation in thermal reaction norms for growth rate: evolution of latitudinal compensation in ectotherms with a genetic constraint. Evolution 61:1577-1589.

Zachariassen, K. E. 1985. Physiology of cold tolerance in insects. Physiological Reviews 65:799-832.

Associate Editor: Ary A. Hoffmann Editor: Mark A. McPeek

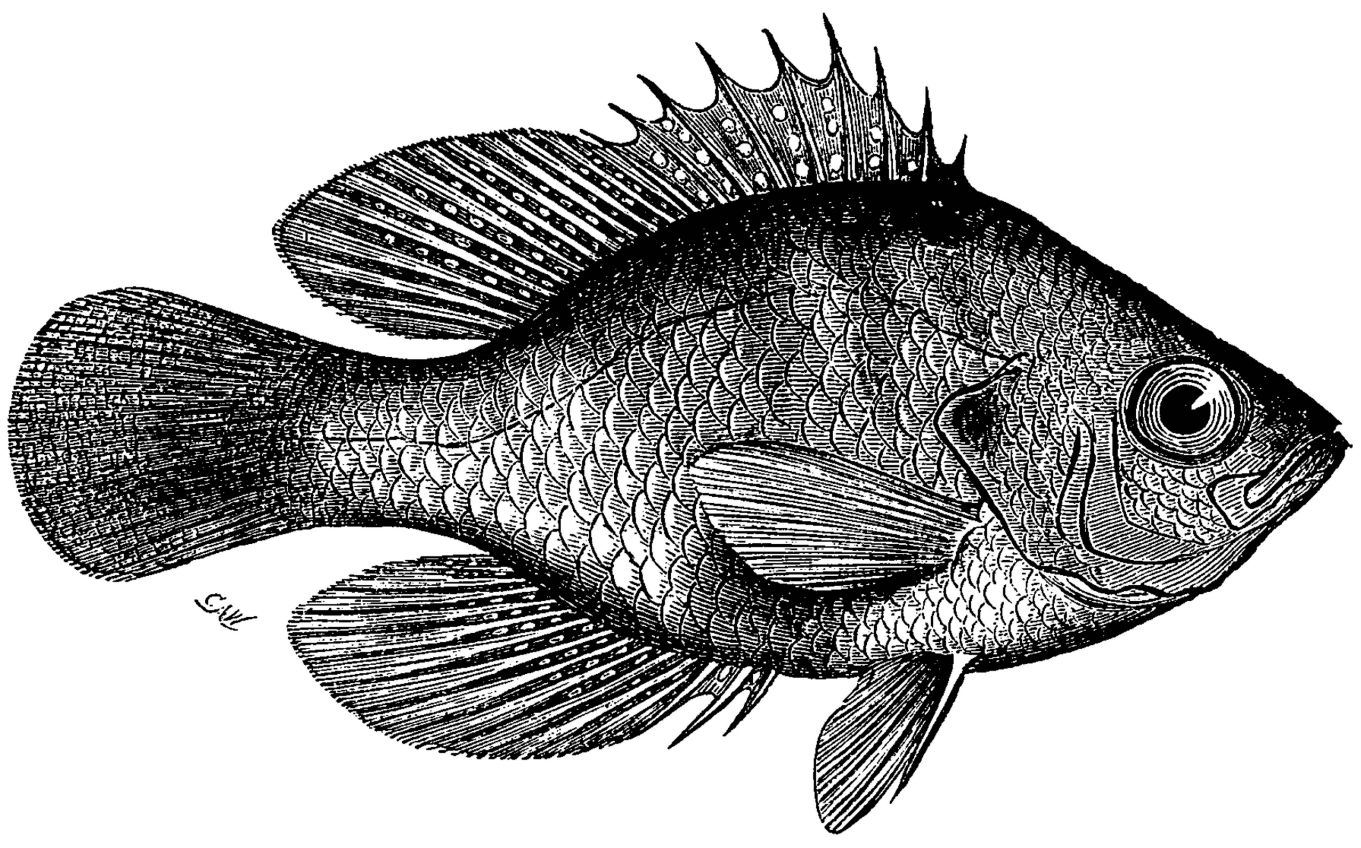

Spotted sunfish Enneacanthus guttatus, from “Mud-Loving Fishes” by Charles C. Abbott (American Naturalist, 1870, 4:385-391). 